(2) Open Access Full Text Article

\title{
Association between the ERCCI rs II6I5 polymorphism and clinical outcomes of oxaliplatin-based chemotherapies in gastrointestinal cancer: a meta-analysis
}

\author{
This article was published in the following Dove Press journal: \\ OncoTargets and Therapy \\ 16 March 2015 \\ Number of times this article has been viewed
}

\author{
Shou-Cheng Ma ${ }^{1, *}$ \\ Yue Zhao ${ }^{2, *}$ \\ Tao Zhangl,* \\ Xiao-Ling Ling' \\ Da Zhao' \\ 'Department of Oncology, \\ ${ }^{2}$ Department of Gastroenterology, \\ The First Hospital of Lanzhou \\ University (The Branch Hospital \\ of Donggang), Lanzhou, Gansu \\ Province, People's Republic of China \\ *These authors contributed equally \\ to this work
}

\begin{abstract}
Purpose: The relationship between the excision repair cross-complementing 1 (ERCC1) rs11615 polymorphism $(\mathrm{C} / \mathrm{T})$ and responses to oxaliplatin-based chemotherapy for gastric cancer (GC) and colorectal cancer (CRC) patients is controversial. Therefore, we performed a meta-analysis to assess this relationship.
\end{abstract}

Method: Relevant studies were retrieved by searching the PubMed database. A systematic review and meta-analysis was performed to evaluate the predictive value of the ERCC1 rs 11615 polymorphism for the clinical outcomes of GC and CRC patients receiving oxaliplatin-based chemotherapy. Therapeutic response to chemotherapy, progression-free survival (PFS), and overall survival (OS) were analyzed.

Results: A total of 22 studies were included in this meta-analysis, including 1,242 cases of GC and 1,772 cases of CRC. For the ERCC1 rs11615 polymorphism, the T allele was associated with a reduced response to chemotherapy in Asians and GC patients $(P<0.05)$. On the other hand, the $\mathrm{T}$ allele was associated with a significant increase in the risk for shorter PFS and OS in all patients (PFS: hazard ratio $[\mathrm{HR}]=1.22, P<0.001,95 \%$ confidence interval $[\mathrm{CI}]=0.93-1.51$ and OS: $\mathrm{HR}=1.12, P<0.001,95 \% \mathrm{CI}=0.85-1.40$ ).

Conclusion: The ERCC1 rs11615 polymorphism was closely associated with the clinical outcomes of GC and CRC patients treated with oxaliplatin-based chemotherapy.

Keywords: ERCC1 rs11615, polymorphism, oxaliplatin-based chemotherapy, gastric cancer, colorectal cancer, meta-analysis

\section{Introduction}

Gastrointestinal cancer, including gastric cancer (GC) and colorectal cancer (CRC), is a major health problem that accounts for a large proportion of all human malignancies; ${ }^{1}$ approximately 3.25 million people are diagnosed with the disease each year worldwide. ${ }^{2}$ Despite recent advances in the diagnosis and therapy of this disease, most gastrointestinal cancer patients present with advanced disease with poor prognoses and low survival rates. Chemotherapy for advanced gastrointestinal cancer has some advantages over best supportive care, including improved quality of life; however, survival does not increase dramatically, with the overall survival (OS) ranging from 6.0 to 12.0 months with chemotherapy. ${ }^{3}$ Combination treatment with 5-fluorouracil/ leucovorin plus oxaliplatin (FOLFOX) is now considered the standard treatment for GC and CRC, with a response rate of over $40 \%$ for first-line treatment. ${ }^{4}$ Oxaliplatin is a frequently used agent that is part of many chemotherapy regimens used to treat several gastrointestinal cancers. It is an organoplatinum complex that can produce both
Correspondence: Da Zhao Department of Oncology, The First Hospital of Lanzhou University (The Branch Hospital of Donggang), Lanzhou 730000, Gansu Province, People's Republic of China Email Idyyzd@I63.com 
inter- and intra-strand platinum-DNA cross-links that, in turn, lead to the inhibition of DNA replication and transcription. ${ }^{5}$ However, oxaliplatin-based therapies have a critical drawback: tumor cell drug resistance. Although resistance to chemotherapy is multifactorial, DNA repair plays a key role in the resistance of tumors to oxaliplatin.

Excision repair cross-complementing 1 (ERCC1) is a gene encoding a protein of the nucleotide excision repair (NER) complex, which is a group of proteins that are able to repair the DNA damage induced by substances forming adducts, such as platinum. ${ }^{6}$ In the past years, the role of single-nucleotide polymorphisms (SNPs) in ERCC1 as predictive factors for treatment outcomes in oxaliplatin-based chemotherapy-treated gastrointestinal cancer patients has been extensively investigated; rs11615 is a common SNP in the coding region of the ERCCl gene, and its polymorphisms might predict patients' response to oxaliplatin and the survival of patients with gastrointestinal cancer. However, other studies have suggested that there is no association of the ERCC1 rs 11615 polymorphism with the clinical outcomes of gastrointestinal cancer patients receiving oxaliplatin-based chemotherapy.,8 Thus, we performed this meta-analysis to evaluate the effects of the ERCC1 rs11615 (C/T) polymorphisms on the efficacy of oxaliplatin-based chemotherapy in gastrointestinal cancer patients by assessing therapeutic response, progression-free survival (PFS), and OS.

\section{Materials and methods Publication search}

This meta-analysis adheres to the relevant criteria of the preferred reporting items for systemic reviews and metaanalyses statement. ${ }^{9}$ The PubMed database was searched for material published in English; the latest search was updated on December 20, 2014. The searching strategy consisted of combinations of medical subheadings and key words, such as "gastrointestinal cancer" or "gastric cancer" or "colorectal cancer" and "excision repair cross-complementing 1" or "ERCC1" or "ERCC1 rs11615" and "polymorphisms, single-nucleotide polymorphisms" or "polymorphism" and "oxaliplatin." All references cited in the original studies or review articles concerning the relevant topic were retrieved to broaden the search for relevant publications.

\section{Inclusion and exclusion criteria}

In this meta-analysis, publications of studies that met the following criteria were included: 1) inclusion of gastrointestinal cancer patients ( $\mathrm{GC}$ and $\mathrm{CRC}$ ); 2) investigation of the relationship between the $E R C C 1$ rs 11615 polymorphism and response to chemotherapy or survival; 3) restriction of the regimen to oxaliplatin-based chemotherapy for investigation of the response to chemotherapy; 4) primary outcomes of interest of objective response, PFS, or OS; and 5) available data for quantitative synthesis, namely, genotype distribution data for response or hazard ratios (HRs) and 95\% confidence intervals (CIs) for survival. The following exclusion criteria were used: 1) oxaliplatin-based chemotherapy was used as neoadjuvant treatment; 2) abstracts and reviews; 3) studies without available or exact data; 4) written in a non-English language; and 5) repeated or overlapping publications.

\section{Data extraction}

Two authors independently extracted the following items from all of the included studies: name of the first author, publication year of the article, country or area, tumor types (GC or $\mathrm{CRC}$ ), number of patients, chemotherapy regimens, and genotyping method and outcomes. In addition, the response to chemotherapy according to genotype, HRs for OS and PFS, and their 95\% CIs were collected for statistical analysis. We resolved any discrepancies through discussion or by consultation with a third person.

\section{Statistical analysis}

Pooled odds ratio (OR) and corresponding 95\% CIs were calculated to estimate the association strength of the ERCC1 rs 11615 polymorphism (mutant gene vs wild-type gene, TT + CT vs CC) with the response to oxaliplatin-based chemotherapy. PFS and OS were evaluated by using pooled Cox proportional HRs and 95\% CIs. A chi-square-based $Q$-test was used to test the assumption of heterogeneity. $P>0.1$ for the $Q$-test suggested a lack of heterogeneity among studies and required the use of the fixed-effects model (the MantelHaenszel method) to estimate the pooled OR of all studies. Otherwise, the random effects model was used. Statistical analyses were performed using STATA statistical software (Version 10.0, StataCorp LP, College Station, TX, USA). $P<0.05$ was considered statistically significant, and all $P$-values were two sided.

\section{Results \\ Characteristics of studies}

In this meta-analysis, 22 studies were identified to evaluate the relationship between the ERCC1 rs11615 polymorphism and the clinical outcomes of oxaliplatin-based chemotherapy in GC and CRC patients. ${ }^{10-31}$ A total of 3,014 patients with gastrointestinal cancer were enrolled in this study, including 1,242 with GC and 1,772 with CRC. There 
were 12 studies from Asian populations ${ }^{11,12,16-19,21-24,26,28}$ and 10 from Caucasian populations. ${ }^{10,13-15,20,25,27,29-31}$ Oxaliplatinbased chemotherapy was investigated in all studies, and FOLFOX was the most popular regimen. The most common genotyping methods were polymerase chain reaction and restriction fragment length polymorphism analysis. Characteristics of the eligible studies are summarized in Table 1 .

\section{Association between the ERCCI rsII6I5 polymorphism and therapeutic response}

Fourteen studies including 1,879 patients qualified for analysis of the association between the ERCC1 rs11615 polymorphism and therapeutic response in GC and CRC patients. In the dominant model, the mutant gene was not associated with the objective response for all patients (TT + CT vs CC: OR $=1.09, P=0.337,95 \% \mathrm{CI}=0.92-1.28)$ (Figure 1). However, stratified analysis by ethnicity showed a significant difference in the estimates of the effect between Asians and Caucasians, with the $\mathrm{T}$ allele being associated with a significantly lower objective response rate in Asians (TT + CT vs CC: OR =1.25, $P<0.001,95 \% \mathrm{CI}=1.14-1.38)$. In addition, in a stratified analysis according to tumor site, the mutant gene was associated with the objective response in GC patients (TT + CT vs CC: OR $=1.18, P=0.004,95 \%$ $\mathrm{CI}=1.05-1.38$ ) (Table 2).

\section{Association between the ERCCI rs II6I5 polymorphism and PFS}

Data from 13 included studies (including 1,464 patients) were applicable for the analysis. As shown in Figure 2, the $\mathrm{T}$ allele was associated with a significant increase in the risk of shorter PFS in all patients (TT + CT vs CC: HR $=1.22$, $P<0.001,95 \%$ CI $=0.93-1.51$ ). Similarly, we also performed stratified analysis by ethnicity and the tumor site, as shown in Table 2.

Table I Study characteristics

\begin{tabular}{|c|c|c|c|c|c|c|}
\hline Study & Area & $\mathbf{N}$ & $\begin{array}{l}\text { Tumor } \\
\text { types }\end{array}$ & $\begin{array}{l}\text { Genotyping } \\
\text { method }\end{array}$ & $\begin{array}{l}\text { Chemotherapy } \\
\text { regimen }\end{array}$ & Outcome \\
\hline Martinez-Balibrea et al ${ }^{10}$ & Spain & 95 & $\mathrm{mCRC}$ & PCR-RFLP & FOLFOX or XELOX & PFS \\
\hline Chang et $\mathrm{al}^{\prime \prime}$ & Taiwan & 168 & CRC & PCR-RFLP & FOLFOX & TR, PFS, OS \\
\hline Chen et $\mathrm{al}^{12}$ & Taiwan & 166 & $\mathrm{mCRC}$ & PCR-RFLP & FOLFOX & TR, OS \\
\hline Chua et $\mathrm{al}^{13}$ & Australia & 118 & $\mathrm{mCRC}$ & PCR-RFLP & FOLFOX & PFS, OS \\
\hline Goekkurt et al ${ }^{14}$ & Germany & 134 & GC & PCR-RFLP & FOLFOX & $\mathrm{TR}$ \\
\hline Etienne-Grimaldi et al $^{15}$ & France & 117 & CRC & PCR-RFLP & FOLFOX & TR, PFS, OS \\
\hline Huang et $\mathrm{al}^{16}$ & $\begin{array}{l}\text { People's Republic } \\
\text { of China }\end{array}$ & 89 & GC & PCR-LDR & FOLFOX & PFS, OS \\
\hline Huang et al ${ }^{17}$ & $\begin{array}{l}\text { People's Republic } \\
\text { of China }\end{array}$ & 102 & GC & PCR-LDR & FOLFOX & PFS, OS \\
\hline Keam et $\mathrm{al}^{18}$ & Korea & 73 & GC & PCR-RFLP & FOLFOX & TR, PFS, OS \\
\hline Kumamoto et al ${ }^{19}$ & Japan & 63 & $\mathrm{mCRC}$ & PCR-RFLP & FOLFOX & TR \\
\hline Lamas et $\mathrm{al}^{20}$ & Spain & 72 & $\mathrm{mCRC}$ & PCR-RFLP & FOLFOX & TR \\
\hline Li et $\mathrm{al}^{21}$ & $\begin{array}{l}\text { People's Republic } \\
\text { of China }\end{array}$ & 335 & CRC & PCR-RFLP & FOLFOX & OS \\
\hline Liang et $\mathrm{al}^{22}$ & $\begin{array}{l}\text { People's Republic } \\
\text { of China }\end{array}$ & 113 & CRC & TaqMan-PCR & FOLFOX or XELOX & TR, PFS, OS \\
\hline Liu et $\mathrm{al}^{23}$ & $\begin{array}{l}\text { People's Republic } \\
\text { of China }\end{array}$ & 116 & GC & TaqMan-PCR & FOLFOX & PFS, OS \\
\hline Lu et $\mathrm{al}^{24}$ & $\begin{array}{l}\text { People's Republic } \\
\text { of China }\end{array}$ & 447 & GC & TaqMan-PCR & FOLFOX & TR, OS \\
\hline Paré et $\mathrm{al}^{25}$ & Spain & 126 & CRC & TaqMan-PCR & FOLFOX & TR, PFS, OS \\
\hline Qi et $\mathrm{al}^{26}$ & $\begin{array}{l}\text { People's Republic } \\
\text { of China }\end{array}$ & 206 & GC & RT-PCR & FOLFOX & $\mathrm{TR}$ \\
\hline Ruzzo et $\mathrm{al}^{27}$ & Italy & 166 & CRC & PCR-RFLP & FOLFOX & PFS \\
\hline Seo et $\mathrm{al}^{28}$ & Korea & 75 & GC & PCR-RFLP & FOLFOX & TR, PFS, OS \\
\hline Spindler et $\mathrm{al}^{29}$ & Denmark & 66 & CRC & PCR & XELOX & $\mathrm{TR}$ \\
\hline Stoehlmacher et $\mathrm{al}^{30}$ & USA & 106 & CRC & PCR-RFLP & FOLFOX & PFS, OS \\
\hline Viguier et $\mathrm{al}^{3 !}$ & France & 61 & CRC & PCR & FOLFOX & TR \\
\hline
\end{tabular}

Abbreviations: N, number of patients; mCRC, metastatic colorectal cancer; PCR-RFLP, polymerase chain reaction-restriction fragment length polymorphism; FOLFOX, 5-fluorouracil plus oxaliplatin; XELOX, capecitabine plus oxaliplatin; PFS, progression-free survival; CRC, colorectal cancer; TR, therapeutic response; OS, overall survival; GC, gastric cancer; PCR-LDR, polymerase chain reaction-ligation detection reaction; PCR, polymerase chain reaction; RT-PCR, reverse transcription-polymerase chain reaction. 
Study

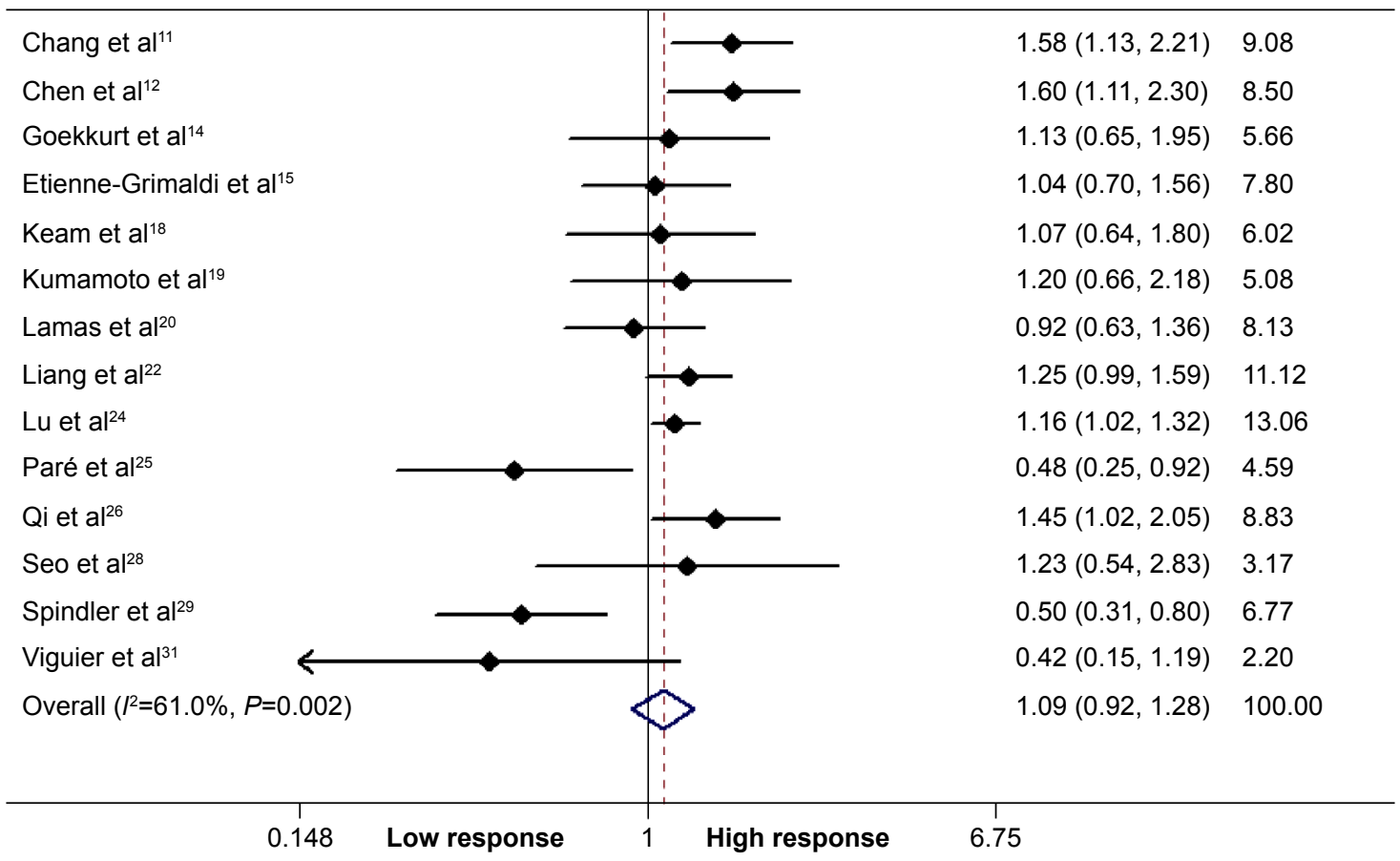

Figure I Association of the ERCCI rs II6I5 polymorphism with response to oxaliplatin-based chemotherapy. Note: Weights are from random-effects analysis.

Abbreviations: $\mathrm{ERCCI}$, excision repair cross-complementing I; $\mathrm{HR}$, hazard ratio; $\mathrm{Cl}$, confidence interval.

\section{Association between the ERCCI rs II6I5 polymorphism and OS}

Fourteen studies including 2,078 subjects were included in the final analysis. There was a significant effect of the ERCC1 rs11615 polymorphism on OS in all patients (TT + CT vs CC: $\mathrm{HR}=1.12, P<0.001,95 \% \mathrm{CI}=0.85-1.40$ ) (Figure 3).
In subgroup analysis stratified by ethnicity and tumor site, the significant differences were retained, as shown in Table 2.

\section{Discussion}

Oxaliplatin-based chemotherapy is the primary therapeutic option for gastrointestinal cancer, especially for advanced or

Table 2 Association between the ERCCI rsII6I5 polymorphism and therapeutic response, PFS, and OS

\begin{tabular}{|c|c|c|c|c|c|}
\hline & Studies & OR/HR (95\% CI) & Z-value & $P$-value & $I^{2}(\%)$ \\
\hline \multicolumn{6}{|c|}{ Therapeutic response } \\
\hline Asian & 8 & $1.25(1.14,1.38)$ & 4.58 & $<0.001$ & 0.0 \\
\hline Caucasian & 6 & $0.75(0.54,1.04)$ & 1.73 & 0.083 & 56.8 \\
\hline GC & 5 & $1.18(1.05,1.38)$ & 2.85 & 0.004 & 0.0 \\
\hline CRC & 9 & $0.98(0.74,1.30)$ & 0.14 & 0.889 & 74.4 \\
\hline \multicolumn{6}{|l|}{ PFS } \\
\hline Asian & 8 & $1.49(1.05,1.92)$ & 6.72 & $<0.001$ & 58.9 \\
\hline Caucasian & 5 & $0.91(0.59,1.24)$ & 6.74 & $<0.001$ & 59.2 \\
\hline GC & 5 & $1.25(0.82,1.67)$ & 5.73 & $<0.001$ & 48.8 \\
\hline CRC & 8 & $1.21(0.80,1.62)$ & 5.83 & $<0.001$ & 74.2 \\
\hline \multicolumn{6}{|l|}{ OS } \\
\hline Asian & 10 & I.2I $(0.86,1.55)$ & 6.87 & $<0.001$ & 61.5 \\
\hline Caucasian & 4 & $1.02(0.44,1.60)$ & 3.44 & 0.001 & 61.1 \\
\hline GC & 6 & $1.15(0.71,1.60)$ & 5.05 & $<0.001$ & 59.2 \\
\hline CRC & 8 & $1.17(0.76,1.58)$ & 5.58 & $<0.001$ & 65.4 \\
\hline
\end{tabular}

Abbreviations: $E R C C I$, excision repair cross-complementing I; PFS, progression-free survival; OS, overall survival; OR/HR, odds ratio/hazard ratio; $\mathrm{Cl}$, confidence interval; GC, gastric cancer; CRC, colorectal cancer; PFS, progression-free survival; OS, overall survival. 


\section{Study}

Martinez-Balibrea et al $^{10}$

Chang et $\mathrm{al}^{11}$

Chua et $\mathrm{al}^{13}$

Etienne-Grimaldi et al $^{15}$

Huang et $\mathrm{al}^{16}$

Huang et al ${ }^{17}$

Keam et $\mathrm{al}^{18}$

Liang et $\mathrm{al}^{22}$

Liu et $\mathrm{al}^{23}$

Paré et $\mathrm{al}^{25}$

Ruzzo et $\mathrm{al}^{27}$

Seo et $a^{28}$

Stoehlmacher et al ${ }^{30}$

Overall $\left(I^{2}=67.6 \%, P=0.000\right)$

\section{HR $(95 \% \mathrm{Cl}) \quad$ Weight \%}

\begin{tabular}{ll}
$0.95(0.53,1.71)$ & 8.74 \\
$2.60(1.77,3.82)$ & 5.12 \\
$2.62(1.14,6.02)$ & 1.31 \\
$0.77(0.48,1.23)$ & 11.06 \\
$1.64(0.95,2.83)$ & 5.68 \\
$1.08(0.66,1.79)$ & 9.00 \\
$0.80(0.49,1.31)$ & 10.68 \\
$1.46(0.94,2.27)$ & 7.98 \\
$2.22(1.39,3.54)$ & 4.82 \\
$0.56(0.37,0.86)$ & 12.32 \\
$1.49(0.96,2.29)$ & 7.98 \\
$1.31(0.77,2.23)$ & 7.37 \\
$1.27(0.77,2.11)$ & 7.94 \\
$1.22(0.93,1.51)$ & 100.00 \\
& \\
\hline
\end{tabular}

Figure 2 Correlation between the ERCCI rs II6I5 polymorphism and progression-free survival.

Note: Weights are from random-effects analysis.

Abbreviations: $\mathrm{ERCCI}$, excision repair cross-complementing I; $\mathrm{HR}$, hazard ratio; $\mathrm{Cl}$, confidence interval.

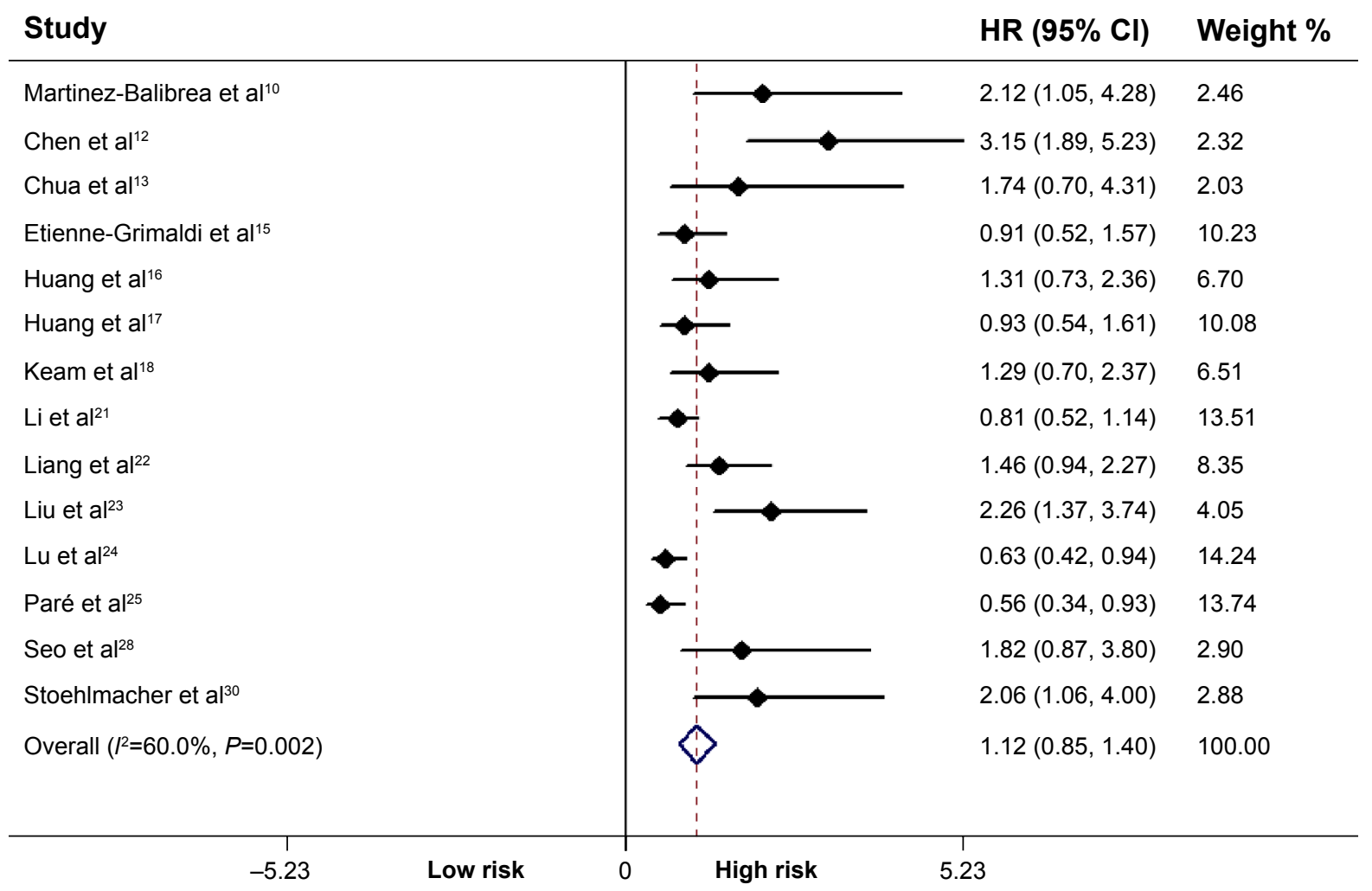

Figure 3 Correlation between the ERCCI rs II6I5 polymorphism and overall survival.

Note: Weights are from random-effects analysis.

Abbreviations: $\mathrm{ERCCI}$, excision repair cross-complementing I; $\mathrm{HR}$, hazard ratio; $\mathrm{Cl}$, confidence interval. 
relapsed cancer. The mechanism of action of platinum agents is based on the formation of DNA adducts that result in the alteration of the DNA structure and, eventually, the inhibition of DNA replication and transcription. ${ }^{32}$ Hence, the expression of genes involved in the mechanisms of DNA repair has been studied as a possible predictive factor in patients treated with platinum-based chemotherapy. ${ }^{33}$ ERCC1, which has a variety of gene forms, is the lead enzyme in the NER DNA repair pathway. ${ }^{34}$ The DNA repair system plays a vital role in maintaining the stability of cellular functions and genomic integrity through the reversal of the DNA damage induced by various endogenous and/or exogenous factors, including therapeutic agents; therefore, host DNA repair capacity may contribute to cancer patient outcomes. ${ }^{35}$ One possible theory postulates that in the absence of platinum therapy, poor DNA repair may result in more biologically aggressive tumors through their susceptibility to greater genetic aberrations over time, resulting in worse outcomes. ${ }^{36}$

The different polymorphisms of ERCC1 may be related to the effect of chemotherapy in cancer patients. ERCC1 rs11615 (C to T), belonging to the NER pathway, is associated with its diminished expression levels (mRNA and protein), with downstream functional consequences in the repair of cisplatin-induced DNA lesions. Recently, the ERCC1 rs11615 gene polymorphism was shown to provide better prognostic information for cancer patients treated with platinum-based chemotherapy, including those with non-small cell lung cancer, ovarian cancer, testicular germ cell tumors, and gastrointestinal cancer. ${ }^{37-40}$ Previous studies have revealed that ERCC1 rs11615 genotypes are associated with the clinical outcome of GC or CRC patients who receive oxaliplatin-based chemotherapy, but the end results of these studies are not consistent, and current evidence is insufficient to confirm a statistically significant correlation. Some references describing association of rs11615 with ERCC1 diminished expression. ${ }^{7,8,25,29,31}$ This meta-analysis examined the association between the ERCC1 rs11615 polymorphism and the clinical outcomes of gastric and CRCs that were treated by oxaliplatin-based chemotherapy. Therapeutic response, PFS, and OS were used as the main parameters. We found no statistical evidence for an association between two ERCC1 rs11615 SNPs and the objective response for all patients. However, stratified analysis indicated the ERCC1 rs11615 T allele was a biomarker of low therapeutic response in Asian patients and GC patients. At the same time, our meta-analysis provided evidence that the ERCC1 rs11615 polymorphism was associated with PFS or OS. Notably, there was an apparent ethnic discrepancy in the prognostic value between Asians and Caucasians, and statistical tests also confirmed the existence of ethnic differences in the estimates of the effect of the ERCC1 allele. This discrepancy could be explained by the fact that the treatment outcome of platinum agents may be influenced by gene-gene interactions in different genetic backgrounds and gene-environment interactions in different lifestyles. As the previous studies gave controversial results, there may be some other reasons, such as the following: 1) different pathological types ( $\mathrm{GC}$ and $\mathrm{CRC}$ ) may produce different results; 2) there was different incidences of GC or CRC in different regions of worldwide, for example, higher incidence of GC in East Asia; 3 ) the positive result of some studies might be attributed to small sample size; 4) the other factors of population included cannot be analyzed in detail, such as age, sex, smoking, and drinking status, which could make the result masked; and 5) some studies are hospital-based design, which would not represent the people who live in a certain region.

Attention should be paid to the limitations of the metaanalysis, although some effort was made to perform a precise and comprehensive analysis. First, there are very few studies comparing Asians and Caucasians, with even fewer involving the black population. Further, with original data lacking for every study, we could only present an extensive subgroup analysis. In addition, the differences in national characteristics in different regions are influencing factors in the study results. Oxaliplatin is used with 5-fluorouracil in the regimen, and not as a single compound, and owing to the limited available publications on the subject, the latent gene-gene associations between NER variants and folatemetabolizing gene variants still cannot be investigated. Finally, some confounding factors such as sex, age, TNM stage, and chemotherapy regimens can never change the results based on the initial data.

To summarize, polymorphisms of ERCC1 rs11615 are closely associated with the clinical outcomes of GC and CRC patients treated with oxaliplatin-based chemotherapy. Future studies with larger sample sizes using multivariant analyses may provide more persuasive data on this putative association.

\section{Disclosure}

The authors report no conflicts of interest in this work.

\section{References}

1. Ong J, Salomon J, te morsche RH, et al. Polymorphisms in the insulinlike growth factor axis are associated with gastrointestinal cancer. PLoS One. 2014;9(3):e90916.

2. Ferlay J, Shin HR, Bray F, Forman D, Mathers C, Parkin DM. Estimates of worldwide burden of cancer in 2008: GLOBOCAN 2008. Int J Cancer. 2010;127(12):2893-2917. 
3. Yamaguchi NH, Mayer IA, Malzyner A, et al. Gefitinib and celecoxib in advanced metastatic gastrointestinal tumors: a pilot feasibility study. J Gastrointest Oncol. 2014;5(1):57-66.

4. Yin M, Yan J, Martinez-Balibrea E, et al. ERCC1 and ERCC2 polymorphisms predict clinical outcomes of oxaliplatin-based chemotherapies in gastric and colorectal cancer: a systemic review and meta-analysis. Clin Cancer Res. 2011;17(6):1632-1640.

5. Afonseca SO, Cruz FM, Cubero Dde I, et al. Vitamin E for prevention of oxaliplatin-induced peripheral neuropathy: a pilot randomized clinical trial. Sao Paulo Med J. 2013;131(1):35-38.

6. Martin LP, Hamilton TC, Schilder RJ. Platinum resistance: the role of DNA repair pathways. Clin Cancer Res. 2008;14(5):1291-1295.

7. van Huis-Tanja LH, Kweekel DM, Lu X, et al. Excision repair cross complementation group 1 (ERCC1) C118T SNP does not affect cellular response to oxaliplatin. Mutat Res. 2014;759:37-44.

8. Zaanan A, Dalban C, Emile JF, et al. ERCC1, XRCC1 and GSTP1 single nucleotide polymorphisms and survival of patients with colon cancer receiving oxaliplatin-based adjuvant chemotherapy. J Cancer. 2014;5(6):425-432.

9. Panic N, Leoncini E, de Belvis G, Ricciardi W, Boccia S. Evaluation of the endorsement of the preferred reporting items for systematic reviews and meta-analysis (PRISMA) statement on the quality of published systematic review and meta-analyses. PLoS One. 2013;8(12) e83138.

10. Martinez-Balibrea E, Abad A, Aranda E, et al. Pharmacogenetic approach for capecitabine or 5-fluorouracil selection to be combined with oxaliplatin as first-line chemotherapy in advanced colorectal cancer. Eur J Cancer. 2008;44(9):1229-1237.

11. Chang PM, Tzeng CH, Chen PM, et al. ERCC1 codon $118 \mathrm{C} \rightarrow \mathrm{T}$ polymorphism associated with ERCC1 expression and outcome of FOLFOX-4 treatment in Asian patients with metastatic colorectal carcinoma. Cancer Sci. 2009;100(2):278-283.

12. Chen YC, Tzeng CH, Chen PM, et al. Influence of GSTP1 I105V polymorphism on cumulative neuropathy and outcome of FOLFOX-4 treatment in Asian patients with colorectal carcinoma. Cancer Sci. 2010; 101(2):530-535.

13. Chua W, Goldstein D, Lee CK, et al. Molecular markers of response and toxicity to FOLFOX chemotherapy in metastatic colorectal cancer. Br J Cancer. 2009;101(6):998-1004.

14. Goekkurt E, Al-Batran SE, Hartmann JT, et al. Pharmacogenetic analyses of a phase III trial in metastatic gastroesophageal adenocarcinoma with fluorouracil and leucovorin plus either oxaliplatin or cisplatin: a study of the arbeitsgemeinschaft internistische onkologie. J Clin Oncol. 2009;27(17):2863-2873.

15. Etienne-Grimaldi MC, Milano G, Maindrault-Goebel F, et al. Methylenetetrahydrofolate reductase (MTHFR) gene polymorphisms and FOLFOX response in colorectal cancer patients. $\mathrm{Br} J \mathrm{Clin}$ Pharmacol. 2010;69(1):58-66.

16. Huang ZH, Hua D, Du X, et al. ERCC1 polymorphism, expression and clinical outcome of oxaliplatin-based adjuvant chemotherapy in gastric cancer. World J Gastroenterol. 2008;14(41):6401-6407.

17. Huang ZH, Hua D, Du X. Polymorphisms in p53, GSTP1 and $\mathrm{XRCC} 1$ predict relapse and survival of gastric cancer patients treated with oxaliplatin-based adjuvant chemotherapy. Cancer Chemother Pharmacol. 2009;64(5):1001-1007.

18. Keam B, Im SA, Han SW, et al. Modified FOLFOX-6 chemotherapy in advanced gastric cancer: results of phase II study and comprehensive analysis of polymorphisms as a predictive and prognostic marker. $B M C$ Cancer. 2008;8:148

19. Kumamoto K, Ishibashi K, Okada N, et al. Polymorphisms of GSTP1, ERCC2 and TS-3'UTR are associated with the clinical outcome of mFOLFOX6 in colorectal cancer patients. Oncol Lett. 2013; 6(3):648-654.

20. Lamas MJ, Duran G, Balboa E, et al. Use of a comprehensive panel of biomarkers to predict response to a fluorouracil-oxaliplatin regimen in patients with metastatic colorectal cancer. Pharmacogenomics. 2011;12(3):433-442.
21. Li HY, Ge X, Huang GM, et al. GSTP1, ERCC1 and ERCC2 polymorphisms, expression and clinical outcome of oxaliplatin-based adjuvant chemotherapy in colorectal cancer in Chinese population. Asian Pac J Cancer Prev. 2012;13(7):3465-3469.

22. Liang J, Jiang T, Yao RY, Liu ZM, Lv HY, Qi WW. The combination of ERCC1 and XRCC1 gene polymorphisms better predicts clinical outcome to oxaliplatin-based chemotherapy in metastatic colorectal cancer. Cancer Chemother Pharmacol. 2010;66(3):493-500.

23. Liu YP, Ling Y, Qi QF, et al. Genetic polymorphisms of ERCC1-118, XRCC1-399 and GSTP1-105 are associated with the clinical outcome of gastric cancer patients receiving oxaliplatin-based adjuvant chemotherapy. Mol Med Rep. 2013;7(6):1904-1911.

24. Lu ZM, Luo TH, Nie MM, et al. Influence of ERCC1 and ERCC4 polymorphisms on response to prognosis in gastric cancer treated with FOLFOX-based chemotherapy. Tumour Biol. 2014;35(4):2941-2948.

25. Paré L, Marcuello E, Altés A, et al. Pharmacogenetic prediction of clinical outcome in advanced colorectal cancer patients receiving oxaliplatin/5fluorouracil as first-line chemotherapy. Br J Cancer. 2008;99(7): 1050-1055.

26. Qi YJ, Cui S, Yang YZ, et al. Excision repair cross-complementation group 1 codon 118 polymorphism, micro ribonucleic acid and protein expression, clinical outcome of the advanced gastric cancer response to first-line FOLFOX-4 in Qinghai-Tibetan plateau population. $J$ Cancer Res Ther. 2013;9(3):410-415.

27. Ruzzo A, Graziano F, Loupakis F, et al. Pharmacogenetic profiling in patients with advanced colorectal cancer treated with first-lineFOLFOX-4 chemotherapy. J Clin Oncol. 2007;25(10):1247-1254.

28. Seo BG, Kwon HC, Oh SY, et al. Comprehensive analysis of excision repair complementation group 1, glutathione S-transferase, thymidylate synthase and uridine diphosphate glucuronosyltransferase 1A1 polymorphisms predictive for treatment outcome in patients with advanced gastric cancer treated with FOLFOX or FOLFIRI. Oncol Rep. 2009;22(1):127-136.

29. Spindler KL, Andersen RF, Jensen LH, Ploen J, Jakobsen A. EGF61 $\mathrm{A}>\mathrm{G}$ polymorphism as predictive marker of clinical outcome to first-line capecitabine and oxaliplatin in metastatic colorectal cancer. Ann Oncol. 2010;21(3):535-539.

30. Stoehlmacher J, Park DJ, Zhang W, et al. A multivariate analysis of genomic polymorphisms: prediction of clinical outcome to 5-FU/ oxaliplatin combination chemotherapy in refractory colorectal cancer. Br J Cancer. 2004;91(2):344-354.

31. Viguier J, Boige V, Miquel C, et al. ERCC1 codon 118 polymorphism is a predictive factor for the tumor response to oxaliplatin/5-fluorouracil combination chemotherapy in patients with advanced colorectal cancer. Clin Cancer Res. 2005;11(17):6212-6217.

32. Petruseva IO, Evdokimov AN, Lavrik OI. Molecular mechanism of global genome nucleotide excision repair. Acta Naturae. 2014;6(1): 23-34.

33. Tiseo M, Bordi P, Bortesi B, et al. ERCC1/BRCA1 expression and gene polymorphisms as prognostic and predictive factors in advanced NSCLC treated with or without cisplatin. Br J Cancer. 2013;108(8): $1695-1703$.

34. Wang Z, Chen JQ, Liu JL, Qin XG, Huang Y. Polymorphisms in ERCC1, GSTs, TS and MTHFR predict clinical outcomes of gastric cancer patients treated with platinum/5-Fu-based chemotherapy: a systematic review. BMC Gastroenterol. 2012;12:137.

35. Li Y, Liu Z, Liu H, et al. ERCC1 and ERCC2 variants predict survival in gastric cancer patients. PLoS One. 2013;8(9):e71994.

36. Bradbury PA, Kulke MH, Heist RS, et al. Cisplatin pharmacogenetics, DNA repair polymorphisms, and esophageal cancer outcomes. Pharmacogenet Genomics. 2009;19(8):613-625.

37. Zhou C, Ren S, Zhou S, et al. Predictive effects of ERCC1 and XRCC3 SNP on efficacy of platinum-based chemotherapy in advanced NSCLC patients. Jpn J Clin Oncol. 2010;40(10):954-960.

38. Mendoza J, Martínez J, Hernández C, et al. Association between ERCC1 and XPA expression and polymorphisms and the response to cisplatin in testicular germ cell tumours. Br J Cancer. 2013;109(1):68-75. 
39. Moxley KM, Benbrook DM, Queimado L, et al. The role of single nucleotide polymorphisms of the ERCC1 and MMS19 genes in predicting platinum-sensitivity, progression-free and overall survival in advanced epithelial ovarian cancer. Gynecol Oncol. 2013;130(2):377-382.
40. Rumiato E, Cavallin F, Boldrin E, et al. ERCC1 C8092A (rs3212986) polymorphism as a predictive marker in esophageal cancer patients treated with cisplatin/5-FU-based neoadjuvant therapy. Pharmacogenet Genomics. 2013;23(11):597-604.

\section{Publish your work in this journal}

OncoTargets and Therapy is an international, peer-reviewed, open access journal focusing on the pathological basis of all cancers, potential targets for therapy and treatment protocols employed to improve the management of cancer patients. The journal also focuses on the impact of management programs and new therapeutic agents and protocols on

\section{Dovepress}

patient perspectives such as quality of life, adherence and satisfaction The manuscript management system is completely online and includes a very quick and fair peer-review system, which is all easy to use. Visit http://www.dovepress.com/testimonials.php to read real quotes from published authors.

Submit your manuscript here: http://www.dovepress.com/oncotargets-and-therapy-journal 